\section{NO. 103}

NOVEMBER

2018

\section{ADB BRIEFS}

\section{KEY POINTS}

- The demographic transition in the People's Republic of China (PRC) is unique in terms of the speed of aging, rising level of the elderly dependency ratio, and limited progress in preparing for it. Aging is progressing fast, even as the country is still developing the necessary soft and hard infrastructure to respond.

- A wide range of policy options can help prepare for a greyer demographic landscape. In particular, policies to respond to the three unique characteristics include (i) recognizing the trend and preparing for rapid aging, (ii) enhancing productivity and number of the working-age population, and (iii) strengthening old age security.

- Going forward, further development efforts can be made in the following areas: elderly care system, financial and fiscal reforms, and age-friendly city.
ISBN 978-92-9261-416-4 (print) ISBN 978-92-9261-417-1 (electronic) ISSN 2071-7202 (print) ISSN 2218-2675 (electronic)

Publication Stock No. BRF189652-2 DOI: http://dx.doi.org/10.22617/BRF189652-2

\title{
Three Features of Aging in the People's Republic of China and Implications for Development Agenda
}

\author{
Akiko Terada-Hagiwara \\ Principal Economist \\ Office of the Director General \\ East Asia Department
}

Hans Van Rijn

Principal Public Management Specialist

Public Management, Financial Sector and Regional

Cooperation Division

East Asia Department

The People's Republic of China's (PRC) demographic transition is unique in terms of its (i) speed, (ii) increase in the elderly dependency ratio, and (iii) the slow progress in preparing for it. Aging is progressing fast, even as the country is still developing the necessary soft and hard infrastructure to respond. In particular, addressing the challenge of developing a longterm elderly care system requires a rethink of delivery models, as well as reforms in pension and insurance systems. Infrastructure development also needs to cater to the needs of elderly citizens. This note provides possible directions to respond to the socioeconomic and fiscal impacts of aging.

\section{UNIQUE FEATURES OF THE AGING PROCESS IN THE PEOPLE'S REPUBLIC OF CHINA}

Two drivers of population aging in the PRC are an increasing life expectancy and a rapidly declining fertility rate. People in the PRC are now expected to live 30 years longer than their counterparts did in 1960, when their life expectancy at birth was merely 44. At the same time, the total fertility rate has declined from 6.2 in the early 1960 s to 1.6 by now. The rate is slightly higher than that of Japan or the Republic of Korea (ROK), the two countries also experiencing fast population aging; but much lower than the 2.4 in India, where the population is still relatively young.

Aging in the PRC differs in three ways compared to other already aged economies. First, the speed of aging is faster in the PRC compared with other higher-income countries such as France, Sweden, or the United Kingdom (UK). For the elderly population (percentage of 
people aged 65 or over) to increase from $7 \%$ to $14 \%$, for example, it took France 115 years, Sweden 85 years, the United States (US) 65 years, and the UK 45 years. However, it is projected that it could be just 25 years for the PRC, a similar trajectory to Japan, where its elderly population ratio rose from $7 \%$ in 1970 to breach $14 \%$ by 1995 (see Figure). This speed, if realized, is one of the fastest among those been observed so far, though Indonesia, the ROK, and Viet Nam may see even faster transition in the future.

Second, the PRC's old age dependency ratio is also rising fast, which implies that the number of working-age adults to support the elderly population is declining relatively faster compared to other countries. The ratio is expected to breach $22 \%$ in 2040 when the PRC is likely to overtake the US. On average, five workers will have to support one elderly person then. The PRC is likely to surpass France by 2055, when every four workers have to care for one elderly person. Both France and the US started their demographic transition much earlier, but the increase in their old-age dependency ratio has been slow partly due to their flexible immigration policies and gradual decline in fertility, which prevented the working-age population from falling. Meanwhile in the PRC, the drastic fall in the fertility rate led to fewer people entering the labor market, resulting in the start of the decline in the working-age population in 2015 .

Third, the PRC's demographic transition is unique in that the country will be aged at a much earlier stage of development compared with many other countries. When the UK's elderly population reached $7 \%$, its per capita gross domestic product (GDP) was $\$ 5,541$ at 1990 international prices; for the US, it was close to $\$ 12,000$; for Japan, about $\$ 10,000$; and the ROK at $\$ 14,000$. But it was $\$ 3,400$ for the PRC in 2000. One implication of this is limited wealth accumulation and relatively low levels of savings of the elderly population by the time the aging process began. The PRC's pension fund assets are still limited at $1.2 \%$ of GDP as of 2014, which is a similar level to Indonesia, where the population is much younger.

In countries where various financial products are available, workers can accumulate assets preparing for their retirement, either through property, funded pensions, and/or personal savings. As a result, they can achieve more financial independence in old age and depend less on government and their families. In this case, population aging will not only pose less strain on family and government support systems, but the accumulated assets are also invested and can contribute to boost productivity of the economy. In the PRC and possibly in other fastaging developing countries, however, the elderly have traditionally been assisted by their families. With declining fertility and weakening family bonds, they will have to rely more on themselves, mainly drawing down on assets they have accumulated during their lifetime. In this case, the assets are not put into productive use, and benefits brought by the accumulated wealth, or so-called second demographic dividend, would be limited.

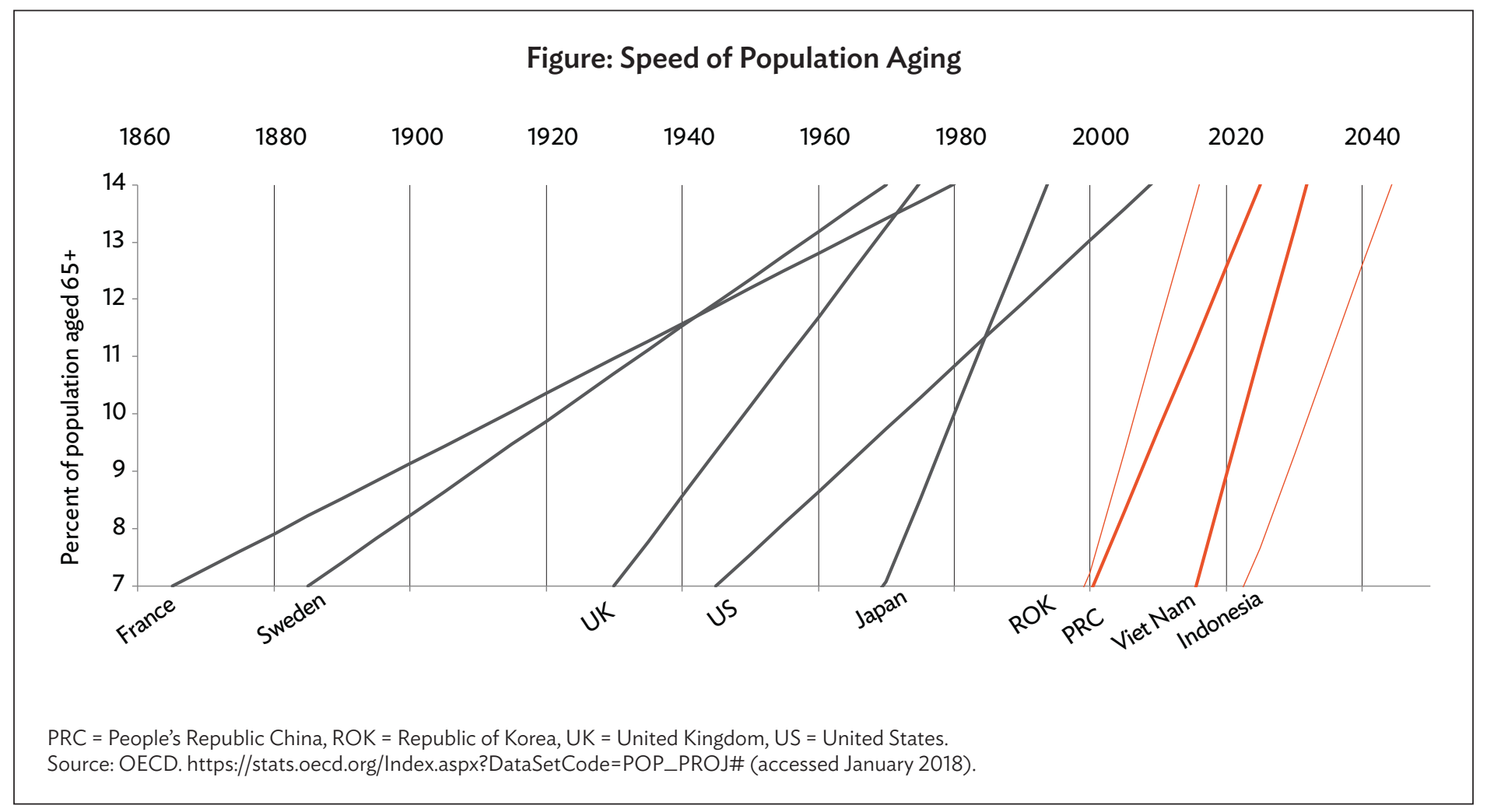




\section{POLICY ACTIONS TO ADDRESS THE CHALLENGES}

The sheer speed and scale of the PRC's population aging, plus its aging at a relatively low income, poses social and economic challenges. A wide range of policy options can help prepare for a greyer demographic landscape. In particular, policies to respond to the three unique characteristics include (i) recognizing the trend and preparing for rapid aging, (ii) enhancing productivity and number of the workingage population, and (iii) strengthening old age security.

\section{Recognizing the Trend and Preparing for Rapid Aging}

In the PRC, as in other Asian economies, a full awareness among public officials at all levels about the rapidly aging population and its implications is still lacking. This is an urgent issue, especially when the speed of aging is so fast. The government could consider setting up agencies or permanent interagency task forces that specialize in demographic issues. Heightened public awareness of demographic trends and their economic effects should give impetus to a number of key reforms that are very important for long-term growth and development. ${ }^{1}$

\section{Enhancing Productivity and Number of Working-Age Population}

Population aging, stemming from declining fertility, reduces the proportion of the working-age population. This calls for improving the productivity of workers through education reform and human capital investments.

Pro-natalist policies can be considered to revive fertility rates. Since the root cause of rapid aging is sharp declines in fertility, reversing or slowing those declines is the primary policy response. While the relaxation of the one-child policy is a good start, much more can be done to boost fertility. Specific policies include fiscal incentives that encourage childbearing and provide a supportive overall environment, e.g., more and better childcare. Also, the concept of working age has to be redefined and updated. The obvious policy implication, especially in countries in the advanced and middle stages of the transition, is to raise the retirement age (footnote 1).

Population aging strengthens the case for training and retraining older Chinese workers. An analysis indicates that in Asia, the lower income of older individuals is only partly due to the fact that relatively few of them are employed. The major cause is their lower productivity and hence lower wages. Training and retraining older workers will not only be beneficial for the workers themselves but will also augment the quantity and quality of the workforce. Also, age-friendly cities with age-friendly infrastructure would help elderly remain productive in the labor market. ${ }^{2}$

\section{Box: Key Challenges to Old-Age Security in PRC}

Pension system. The current pension arrangements in the People's Republic of China are under pressure. First, there is a significant heterogeneity in the pension burden across provincial governments. Second, the lack of pension portability has increasingly led to a loss of built-up pension when individual moves from one jurisdiction to another, and so has undermined social inclusion. Third, the current administrative fragmentation in pension schemes perpetuate unequal outcomes and rampant inefficiencies.

Medical insurance. The current arrangements for medical insurance are characterized by a welfare focus and dominated by the reimbursement of relatively minor medical expenses. Consequently, they should be streamlined to be much more responsive to the medical needs of (i) people suffering from serious illnesses; and (ii) the medical needs of an aging population (e.g., treatment of age-related chronic diseases). Current reimbursement ceilings (from CNY3,000 to CNY10,000) for outpatients are inadequate to cover any major expenses.

Long-term elderly care insurance. Financial arrangements to fund long-term elderly care are at the pilot level at best. The main challenge is to find financially viable solutions for the low- and middle-income households. Currently, the pilot long-term elderly care projects are mainly funded by medical insurance. However, in many localities where this is piloted, the medical insurance fund has run into deficits, which renders this approach financially unsustainable.

Note: $C N Y=$ Chinese Yuan (CNY6.9515 = US\$1 as of 28 Nov 2018).

Source: Asian Development Bank.

S.H. Lee, A. Mason, and D. Park. 2012. Overview: why does population aging matter so much for Asia? Population aging, economic growth, and economic security in Asia. In D. Park, S.H. Lee, and A. Mason, eds., Aging, Economic Growth, and Old-Age Security in Asia. Manila: ADB.

2 D. Park. and K. Shin. 2012. Impact of Population Aging on Asia's Future Growth. In D. Park, S.H. Lee, and A. Mason, eds., Aging, Economic Growth, and Old-Age Security in Asia. Manila: ADB. 
Finally, developing cost-effective and sustainable models for elderly care is a priority. Institution-based elderly care models are very costly and might not be affordable in the context of the PRC. Community and home-based models offer great potential and need to be further developed. To make the service delivery sustainable and efficient, the role of the private sector and the potential for public-private partnership needs to be explored.

\section{Strengthening Old-Age Security}

Rapid population aging creates the risk of widespread old-age poverty in the PRC. Therefore, reducing the economic vulnerability of the large and growing elderly population is an urgent priority. The Box highlights the salient challenges to the achievement of old-age security in PRC.

The first step toward adequate old-age support is to raise public awareness about the need to save for retirement. Relatively easy measures such as simplifying procedures for contributing to pension systems may raise compliance rates. Although financial education and literacy are critical, governments can take measure to provide a broader overall environment in which individuals are better informed and have stronger incentives to make sound financial decisions. ${ }^{3}$

The PRC needs a stronger national pension system. Despite its rapid demographic transition to an older population, the PRC does not yet have efficient, effective national pension systems. Pension reform that ultimately delivers an affordable and sustainable pension system with adequate benefits for a wide segment of the population is an urgent regionwide priority for old-age economic security (footnote 3 ).

Nonetheless, public transfers to the elderly must be kept sustainable and should not significantly weaken the incentives of individuals to save for old age. Precisely because public transfers have played a smaller role in old-age support in the PRC relative to the advanced economies and Latin America, there is greater scope for increasing them in the future. Experience has shown that inappropriate policies and institutions are politically almost impossible to reverse once they become entrenched. The PRC has a great opportunity to build up a robust, efficient, and resilient old-age support system based on a healthy mix of individual responsibility and social risk pooling. ${ }^{4}$

The current arrangements for medical insurance could be streamlined to be much more responsive to the medical needs of people suffering from serious illnesses, and to the medical needs of an aging population (e.g., treatment of age-related chronic diseases). This can be done by adopting a unitary risk pool approach (as opposed to the current welfare-based model), under which expenditure liability is transferred to a pooled arrangement. Pooling ensures that the risk related to financing health interventions is borne by all the members of the pool and not by each contributor individually. Its main purpose is to share the financial risk associated with health interventions for which there is an uncertain need.

The arguments in favor of risk pooling in health care relate to more equitable outcomes and considerable efficiency gains. The equity arguments reflect the view that society does not consider it to be fair that individuals should assume all the risk associated with their health care expenditure needs. Small, fragmented risk pools, which are the norm in developing countries, have contributed to seriously adverse outcomes for health system performance, partly caused by rampant inefficiencies.

As outlined above, for reasons of fiscal sustainability, the financing of long-term elderly care should be distinguished from regular medical insurance arrangements. One approach that can achieve a more effective arrangement is provided by Japan. With the introduction of a public, mandatory program of long-term care insurance in 2000 , Japan has moved toward a system of social care for the frail and elderly. The program covers care that is both home-based and institutional. Fifty percent of the insurance is financed from general tax revenue and the other $50 \%$ from the premiums of the insured. There are two types of insured: (i) those of ages 65 and above and (ii) those who are between the ages of 40 and 64 . The first category of insured is asked to pay a premium deducted from pension, or direct payment for insurer according to their pension status. In the second category, the premium is withheld from the medical insurance premium.

\section{POLICY IMPLICATIONS}

Going forward, further development efforts can be made in the following three areas: (i) elderly care system, (ii) financial and fiscal reforms, and (iii) age-friendly city.

\section{Operational Challenges in Elderly Care}

There is a strong need-backed up by the necessary political will-to identify models and implementation partnerships that can deliver quality and affordable elderly care services in the PRC. Under the Twelfth Five-Year Plan, 2011-2015, a three-tiered system of elderly care services was developed: home-based support (at the core); community-based support (where necessary); and residential care (i.e., nursing homes for the elderly, seen as supplementary). These arrangements, however, suffer from a number of operational weaknesses:

3 D. Park. 2012. Policy options for reforming developing Asia's pensions system. In D. Park, ed., Pension Systems and Old-Age Income Support in East and Southeast Asia: Overview and Reform Direction. New York: Routledge.

4 Q. Chen, K. Eggleston, and L. Li. 2012. Demographic change, intergenerational transfers, and the challenges for social protection systems in the People's Republic of China. In D. Park, S.H. Lee, and A. Mason, eds., Aging, Economic Growth, and Old-Age Security in Asia. Manila: ADB. 
(i) The provision of home- and community-based services is critically undermined by a shortage of funding and skilled workers.

(ii) Targeting of public services to the elderly poor is weak and, as a consequence, care services do not always benefit those elderly who really need them.

(iii) Government subsidies are mainly targeted at residential care providers and are input-based.

Operational reforms to the long-term elderly care system can build on the experiences from the Elderly Care Development Project in Hebei Province, which was designed to have demonstration value for other provinces in the PRC; and the Hubei Yichang Comprehensive Elderly Care Service Demonstration Project. Key innovative operational features of these project included the development of (i) an integrated elderly care service model that links home, community, and residential care and management; (ii) pilot projects to support good practice elderly care system development in areas such as management, quality assurance, and new services development; and (iii) a human resources development program at the tertiary and continuing education levels, which anticipates the growth of the sector and demand for new skills.

\section{Financial and Fiscal Challenges}

Addressing the challenges outlined above all have significant fiscal and financial ramifications, and this should be accounted for in the reform direction going forward. Future efforts could focus on the development of a unified pension system, including a national pooling arrangement, which has recently been announced by General Secretary $X i$. The proposed national pooling arrangement would enhance fiscal sustainability by (i) doing away with inefficiencies; (ii) introducing equalization measures; (iii) strengthening the National Social Security Fund's asset management (i.e., improving rates on investment); and (iv) introducing a more efficient and equitable way of collecting social security contributions.

\section{Elderly-Friendly City}

By harnessing successful development experiences in the transport sector and in addressing challenges of urbanization, the agenda to develop age-friendly cities can be further explored and experimented on. The development agenda will likely be comprehensive, and should involve multiple components ranging from the transport system, to air quality control, to regulatory reform. 
About the Asian Development Bank

$A D B$ is committed to achieving a prosperous, inclusive, resilient, and sustainable Asia and the Pacific, while sustaining its efforts to eradicate extreme poverty. Established in 1966, it is owned by 67 members48 from the region. Its main instruments for helping its developing member countries are policy dialogue, loans, equity investments, guarantees, grants, and technical assistance.

ADB Briefs are based on papers or notes prepared by ADB staff and their resource persons. The series is designed to provide concise, nontechnical accounts of policy issues of topical interest, with a view to facilitating informed debate. The Department of Communications administers the series.

The views expressed in this publication are those of the authors and do not necessarily reflect the views and policies of ADB or its Board of Governors or the governments they represent. ADB encourages printing or copying information exclusively for personal and noncommercial use with proper acknowledgment of ADB. Users are restricted from reselling, redistributing, or creating derivative works for commercial purposes without the express, written consent of $A D B$.

Asian Development Bank

6 ADB Avenue, Mandaluyong City

1550 Metro Manila, Philippines

Tel +6326324444

Fax +6326362444

www.adb.org/publications/series/adb-briefs

This brief benefited from comments provided by Indu Bhushan and Ying Qian.

(c) (1)

Creative Commons Attribution 3.0 IGO license (CC BY 3.0 IGO)

(C) 2018 ADB. The CC license does not apply to non-ADB copyright materials in this publication.

https://www.adb.org/terms-use\#openaccess

http://www.adb.org/publications/corrigenda

pubsmarketing@adb.org 